\title{
Quantitative approach in the spectral reflectance-lithostratigraphy of the Wind River and southern Bighorn basins, Wyoming
}

\section{S. GALVÃO and Í. VITORELLO}

Instituto Nacional de Pesquisas Espaciais-INPE, São José dos Campos, SP, Brasil

(Received 23 November 1993; in final form 2 November 1994)

Abstract. A procedure developed for quantifying spectral variability was applied to visible and near-infrared spectra from a database of the Wind River and Bighorn basins. Principal Components Analysis (PCA) of 94 sedimentary rock spectra distinguished shales, sandstones, limestones, dolostones, bedded gypsum and bentonites from 25 stratigraphic units. However, only twelve spectrally distinct groups were delineated because of lithological homogeneity. Albedo and slope characteristics of the spectra were found to be related to the first and second PC, respectively, and absorption bands related to the remaining components. A second PCA phase, using vertically scaled spectra to minimize the albedo variability, indicated space distributions that enhanced major absorption features in the near-infrared region. Parameters describing absorption bands were also calculated from spectral continuum. The best parameters for spectra discrimination were band depths at 1900,2200 and $2300 \mathrm{~nm}$, in agreement with the PCA results using scaled spectra. Finally, the stratigraphic column was characterized by correlated $\log$ sections composed by PC scores of the original data and of scaled spectra, in lieu of band, band-ratios, area and depths of absorption bands. Reflectance-lithostratigraphic markers were identified in the log sections and indicated the potential of reflectance-lithostratigraphy in correlation studies. We concluded that PCA using a small number of narrow bands to represent the spectrum was an adequate mathematical approach for spectral analysis. PCA of scaled spectra was found to be a useful tool to enhance differentiations due to absorption features.

\section{Introduction}

The area of the Wind River and southern Bighorn basins depicted in figure 1 has been extensively studied by remote sensing, including visible, near-infrared, and

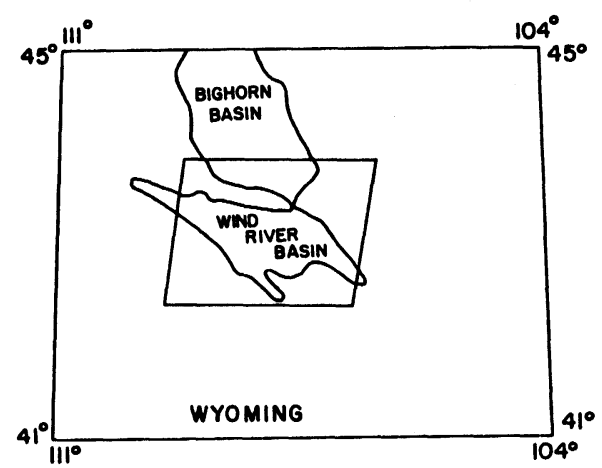

Figure 1. Map of Wyoming with the study area covering the Wind River and southern Bighorn basins (Adapted from Lang 1985).

0143-1161/95 \$10.00 (C) 1995 Taylor \& Francis Ltd 
thermal infrared spectroscopic data (Conel et al. 1985, Lang 1985, Lang et al. 1987, 1990, Stucky et al. 1987). According to Lang et al. (1990), almost 200 spectra have been obtained from samples collected in the area, and they have been qualitatively analysed for the mineralogical nature of sedimentary rocks.

In this paper, our purpose is to present a quantitative analytical approach, based on the use of Principal Components and on the application of the straight-line continuum method (Clark and Roush 1984), as a simplifying alternative in the analysis of sedimentary rock spectra collected by Lang et al. (1990). The questions we seek to answer are: which minimal spectral parameters are sufficient to characterize a large set of rock spectra; which geological units are statistically discriminated and which ones are similar; and which contributions can be provided by this approach to lithostratigraphic correlations in the Wind River and Bighorn sedimentary basins.

\section{Database}

A digital spectral database has been presented by Lang et al. (1990) for the central Wyoming study area of figure 1 . From that database, we selected 94 spectral curves representing outcrop samples (weathered) of 25 formations or members of the Wind River and Bighorn basins. As indicated in table 1, the lithology of these samples spans from siliciclastics to chemical sedimentary rocks. The mineralogy was determined from bulk sample X-ray diffraction (XRD) analysis (Lang et al. 1990). The reflectance spectra were obtained with a Beckman UV5240 spectrophotometer, an integrating sphere and a Halon reference standard. The determinations are, thus, of hemispherical reflectance, in the range of 400 to $2500 \mathrm{~nm}$ and a sampling interval of $1 \mathrm{~nm}$ from 400 to $800 \mathrm{~nm}$, and $4 \mathrm{~nm}$ from 800 to $2500 \mathrm{~nm}$. A bandwidth variation, from $1 \mathrm{~nm}$ at $400 \mathrm{~nm}$ to $40 \mathrm{~nm}$ at $2500 \mathrm{~nm}$, provides a spectral resolution (bandwidth/wavelength) of less than 2 per cent throughout the spectral range. More details are found in Lang et al. (1990).

\section{Methodology for lithospectral characterization}

\section{1: Principal components analysis (PCA)}

PCA is commonly used to produce low dimensionality eigenvectors by which the data set can be rotated (Davis 1986). Several studies have utilized PCA in spectral analysis (Sasaki et al. 1983, Smith et al. 1985, Galvão et al. 1995). In the present work, eigenvectors were used to get information on the spectral separation level of samples and to identify homogeneous groups.

The preliminary step was the selection of a minimal set of narrow bands appropriately positioned in the frequency axis, in such way as to represent the general shape and slopes of all the curves in the data set. The recommended procedure is to draft some curves by using reflectance values from the narrow bands and to compare the drafted curves with the original spectra, for fitness. For example, in figure 2, we indicate the position of 13 bands with wavelength widths of $20 \mathrm{~nm}$, distributed in approximately equal distances in the spectra. We excluded the two major intervals of atmospheric absorptions to allow possible inferences from images from the Wind River and Bighorn basins, based on the results of this paper.

Alternatively, PCA was performed on spectra vertically scaled to unity at $1500 \mathrm{~nm}$ (middle of the interval studied) to minimize albedo variability, and hopefully get a better insight into the factors affecting the eigenvectors of less variability. In this phase, we selected 10 reflectance values obtained at $50 \mathrm{~nm}$ 


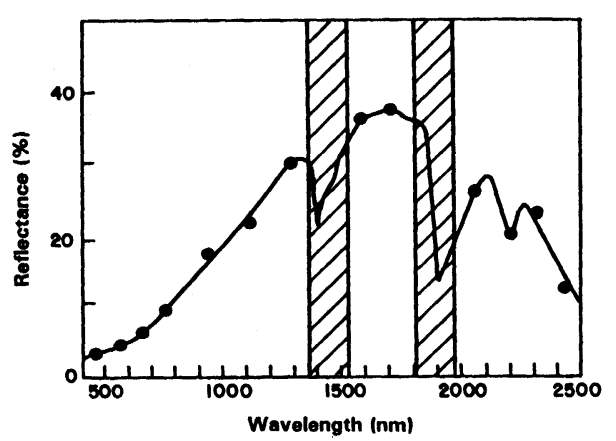

Figure 2. Reflectance spectrum of a siltstone from the Morrison Formation. The dots indicate the wavelength position and the mean reflectance of each selected 13 narrow bands. The two main atmospheric absorption bands are indicated by the stippled areas.

intervals from 2000 to $2500 \mathrm{~nm}$. We used only this interval to make our detailed analysis because of the importance of the spectral variability related to the Al-OH and $\mathrm{CO}_{3}$ absorption bands. A detailed discussion on absorption features registered by the spectra of the Wind River and Bighorn basins is found in Lang et al. (1990). Henceforth, we will refer to these normalized spectra as the scaled data set and the non-normalized spectra as the original data set.

\subsection{Analysis of absorption bands by continuum removal}

In the procedure that uses absorption band characteristics, we made use of the straight-line continuum to isolate and quantify the features with centres around 900 , $1400,1900,2200$ and $2300 \mathrm{~nm}$. These absorption bands were chosen because of their frequent occurrence and good definition in spectra of sedimentary rocks. Since this quantification procedure consisted of a simple mathematical transformation applied individually over each absorption band, without any linear combination of variables, as in the case of PCA, we decided for the inclusion of the bands within the main atmospheric absorption intervals $(1400$ and $1900 \mathrm{~nm})$. Thus, the five absorption bands were analysed individually in terms of the discriminatory power of their parameters.

Continuum removal is a common technique employed in the interpretation of reflectance spectra (e.g., Clark and Roush 1984, and references therein). In our work, each continuum was manually drawn as straight lines from peak to peak on either side of each absorption band (figure 3). A normalized reflectance (NR) was calculated for each wavelength as the ratio of the sample reflectance by the equivalent continuum reflectance. As shown in figure 3, four spectral parameters were resolved for each absorption band: the continuum slope $(S)$ measured from the reflectance difference $(\Delta R)$ divided by the wavelength interval $(\Delta \lambda)$; the maximum depth of absorption $(D)$, defined as 1 minus the normalized reflectance at the wavelength of maximum absorption; the width of the absorption $(W)$, measured at half maximum depth; and the area of the absorption $(A)$, enclosed by the continuum. Spectral similarity relations among the stratigraphic units, based on these parameters, were analysed from scatterdiagrams. 


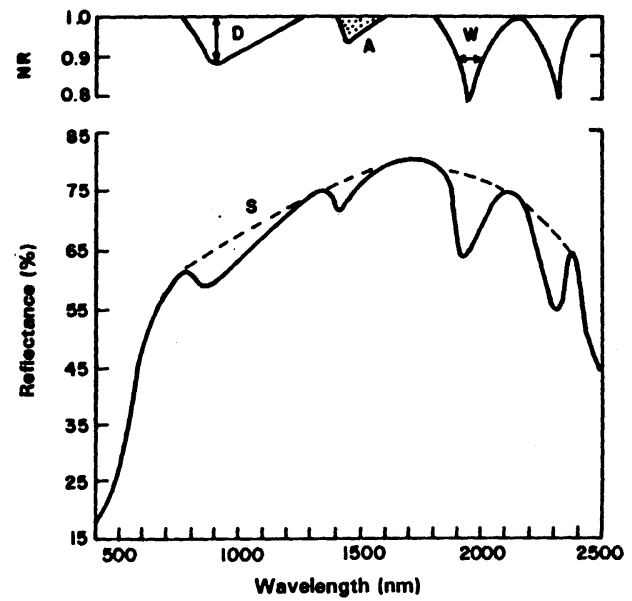

Figure 3. Illustration of the straight-line continuum removal. A spectrum of a dolostone from the Goose Egg Formation is shown in the lower part (solid line). The straight-line continuum is indicated by the dashed line. The upper part displays the normalized reflectance (NR), obtained from the division of the spectrum by the continuum. The absorption parameters are: $S$, slope of the continuum; $D$, maximum depth of the absorption; $W$, width of the absorption at half the maximum depth; $A$, area of the absorption enclosed by the continuum.

Finally, the stratigraphic column was compared with log sections composed by each variable (band, PCA scores and parameters from absorption features), so that reflectance-lithostratigraphic markers could be identified.

\section{Results and discussion}

4.1. Principal components analysis (PCA)

4.1.1. Original data

The eigenvectors obtained from the correlation matrix formed by 13 reflectance bands from 94 spectra are illustrated in figure 4, and the first two PC scores are

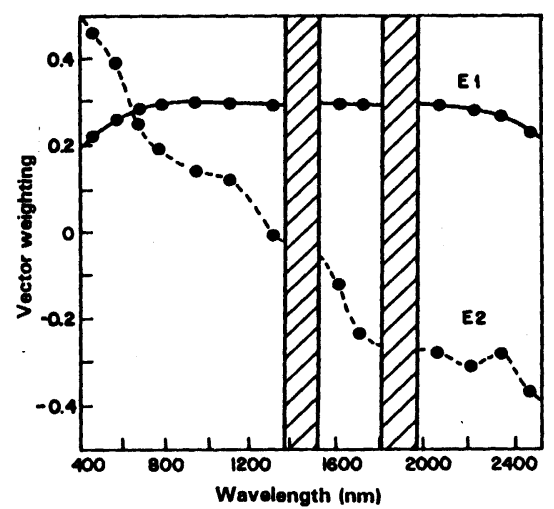

Figure 4. Eigenvectors (E1 and E2) related to the first two principal components derived from 13 narrow bands of 94 reflectance spectra. 


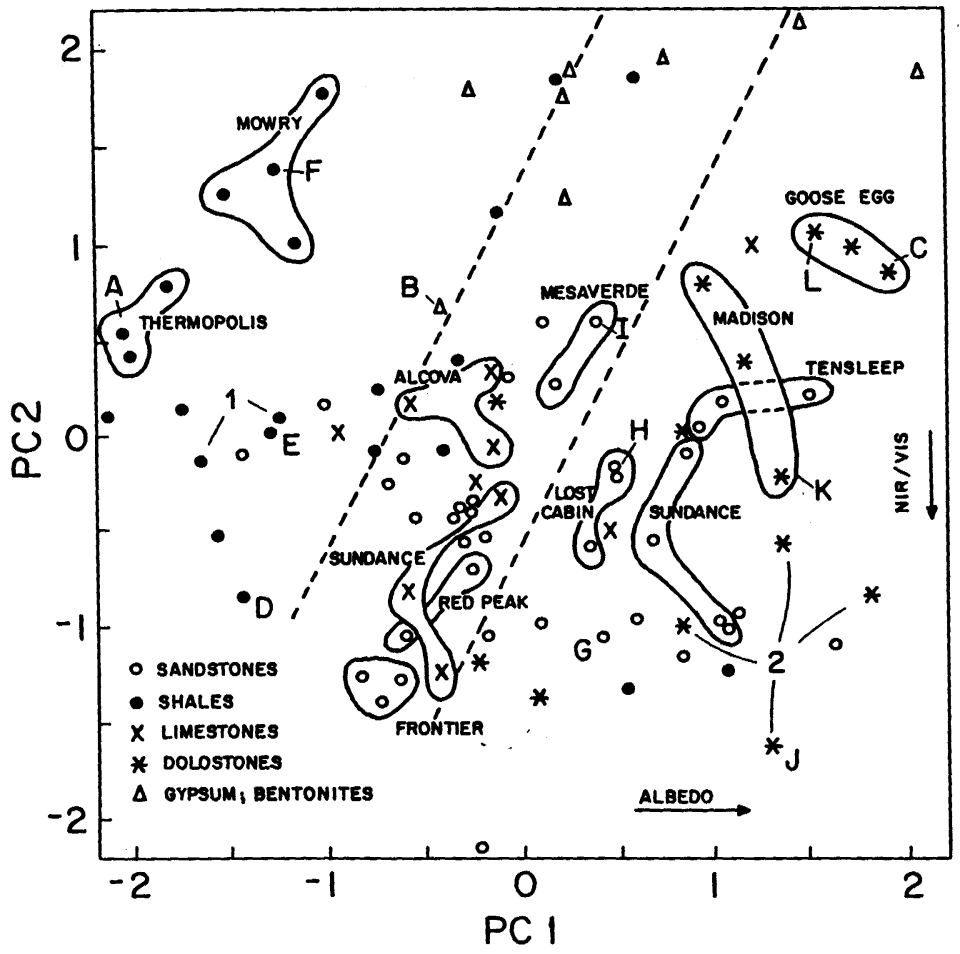

Figure 5. Space distribution of the first two principal components scores (PC1 and PC2) of 94 spectra. The closeness among samples is an indication of similarity. The spectra present higher albedos towards the right side, and higher NIR/VIS ratios towards the bottom. Diagonal dashed lines, arbitrarily drawn, separate zones of shales (left), sandstones, limestones and bedded gypsum (centre), and dolostones, sandstones and bentonites (right). Components of twelve stratigraphic units are enclosed by heavy lines, in order to facilitate discussions. Spectra of samples identified by letters are shown in figures 6 and 7. Samples 1 and 2 are discussed in the text.

shown in figure 5. The analysis of the amplitude, sign and shape of the curve that represent the eigenvector weighting (figure 4) and of the PC space distribution (figure 5) gives an indication of the spectral characteristics that are responsible for the statistical variance of the data set. We infer that the first eigenvector, that describes most of the data set's variability ( 83 per cent of the total variance), can be interpreted as a measure of the albedo variation. The positive weightings of $E 1$ in figure 4 indicate a positive covariance relationship among the 13 reflectance bands. On the other hand, the weightings of E2 in figure 4 indicate a negative association mainly between visible (positive weightings for bands 1,2 and 3) and infrared (negative weightings for bands 11, 12 and 13) reflectance data. As we will illustrate with several spectra, the second eigenvector, with 10 per cent of the total variance, is related to the slopes of the curves.

Figure 5 displays the variance of the data set projected into a space of orthogonal principal components where smaller distances among samples are indicative of similarity. Examination of the PC scores (figure 5) shows a coarse sample separation along the PCl axis. Low albedo shales are located on the left side, high albedo 
dolostones, sandstones and bentonites are found in the right region and medium albedo sandstones, limestones and gypsum are distributed in the middle of figure 5.

Figure 6 displays three spectra $(A, B, C)$ of samples shown in figure 5 by the same reference letters, with increasingly higher albedo towards the right side of the PC1 axis. For the siliciclastics, this trend agrees with an increase in silica content, but a decrease in the clay component, iron oxides and organic matter. In the other direction, as PCl values decrease, the spectra present lower albedos with less conspicuous absorption features probably because of an increase in opaque minerals and carbonaceous material (Hunt and Salisbury 1976).

To get a better understanding of the second eigenvector, we have plotted in figure 7 the spectra of samples with the same albedo (similar PC1 scores), but variable PC2 scores. In figure $7(a)$, we show three shale samples; in $7(b)$ sandstones; and in $7(c)$ dolostones. The position of these samples along PC2 axis is indicated by reference letters in figure 5. Figure 7 shows, in the inset, the near-infrared/visible ratio of each curve. The slopes of the spectra, represented by such ratios, increase from the curves $F, I$ and $L$ (top of PC2 axis in figure 5) to the curves $D, G$ and $J$ (bottom of PC2), respectively. The wavelengths chosen for calculations $(2450 \mathrm{~nm} / 450 \mathrm{~nm})$ represent, respectively, the negative and positive maxima of the second eigenvector (figure 4).

In fact, PC2 expresses an effect of spectral slope inversion between visible and infrared reflectance data, which is well illustrated in figure 7 . Spectra of samples positioned at the top of the PC2 axis (e.g., curve $F$ in figure 7(a), with a descending slope) show higher reflectance in the visible and lower in the infrared than those positioned at the bottom of the PC2 axis (e.g., curve $D$ in figure $7(a)$, with an ascending slope). The slope of each spectrum is probably affected by the net radiation resulting from the interplay of absorption and scattering properties of the minerals present in the rock. For instance, samples with high iron-oxide content but low hydroxyl-bearing minerals would present a high ratio (ascending slope), and vice-versa.

In figure 5, we have delineated by hand groups composed of samples representing twelve stratigraphic units. The remaining samples outside the outlined groups

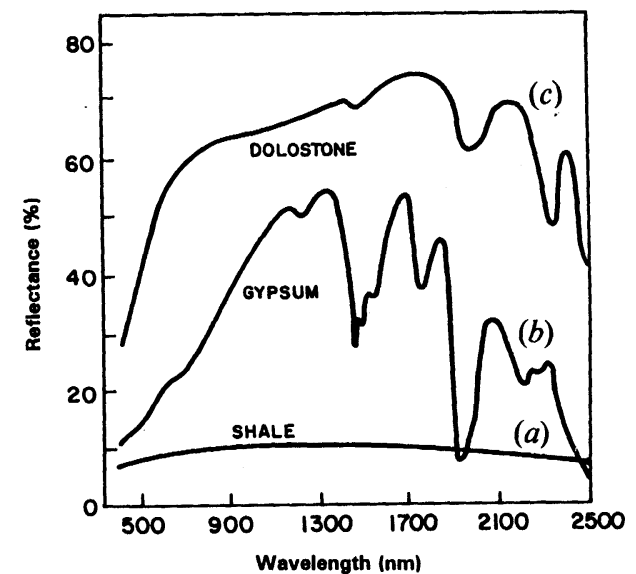

Figure 6. Three spectra illustrating increasingly higher albedo along principal component (PC1) in figure 5. The shale $(a)$ is from the Thermopolis Formation; the bedded gypsum $(b)$ and the dolostone $(c)$ are from the Goose Egg Formation. 

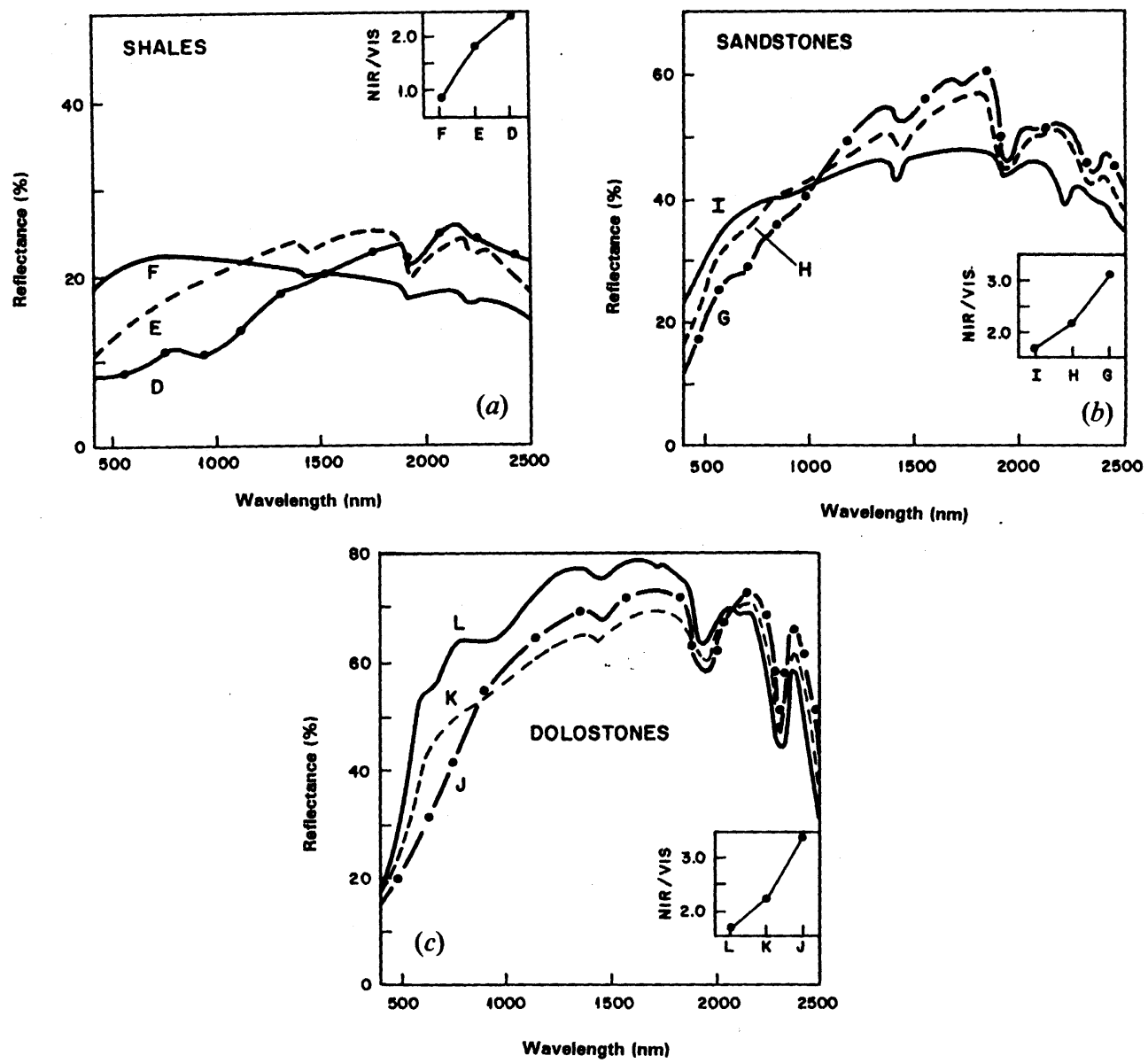

Figure 7. Spectra of shales, sandstones and dolostones, respectively in $7(a),(b)$ and $(c)$, showing changes in curve shapes along the PC2 axis of figure 5. The letter of each curve is related to the space distribution in figure 5. Near-infrared/visible ratios of each curve are plotted in the inset and represent the slopes of the curves.

are either single sample of other stratigraphic units or belong to units that have samples with spectra widely dispersed in the PC space. In this manner, PCA is a good indicator of lithostratigraphic homogeneity or heterogeneity of the unit. Sample dispersion in PC space is probably due to variations in reflectance related to mineralogy, chemistry, granulometry, surface roughness and the presence of a weathered crust or lichen. For example, the enclosed samples of the Thermopolis Formation (figure 5) are composed by smectite-rich shales, but the remaining Thermopolis samples, with higher quartz content, probably responsible for higher albedos (samples indicated by the number 1 in figure 5), are found further to the right. Dolostones from the Goose Egg Formation also fall in two regions. The samples indicated by number 2 in figure 5 present less calcite than the samples in the group further above. These two groups are represented by spectra $J$ and $C$ in figures $7(c)$ and 6, respectively. According to the previous discussion, we can infer that the 
relative position of any spectrum along PC2 is probably related to variations in minor constituents, such as iron oxides and hydroxyl-bearing minerals. For instance, the spectrum of sample $J$ appears to be dominated by the presence of ferric oxides because of the reflectance decrease from the red to the blue interval (Townsend 1987).

\subsubsection{Scaled spectra}

The spectra were shifted vertically at $1500 \mathrm{~nm}$ because most of the slope inversions described before occur in the wavelength interval from 1000 to $2000 \mathrm{~nm}$. With the normalization process, all spectra acquire about the same albedo. As expected, PCA using the scaled spectra was partially successful in removing the albedo variation from the first component. As a result, there is a shifting up of the remaining variation factors into higher eigenvectors. This procedure helps to enhance subtle but important information because these shifted factors are related to the variability of absorption features. For instance, in figure 8 , that describes the weighting factors of the scaled spectra, eigenvector 1 represents the variability 75 per cent of the total variance) related to the residual albedo of the normalized curves. PC2 weighting factors (15 per cent of the total variance) reflect absorption features at $2300 \mathrm{~nm}$ (positive sign) and secondly around $2100 \mathrm{~nm}$ (negative). PC3 factors ( 5 per cent of the total variance) are responsible for features at $2060 \mathrm{~nm}$ (positive), at $2200 \mathrm{~nm}$ (negative), and secondly from 2400 to $2500 \mathrm{~nm}$ (negative).

The scores of principal components 2 and 3 are shown in figure 9 . In this diagram, there is a tendency for the carbonates to be found around the centre and towards the lower left side. There is an increase in the strength of the $2300 \mathrm{~nm}$ band

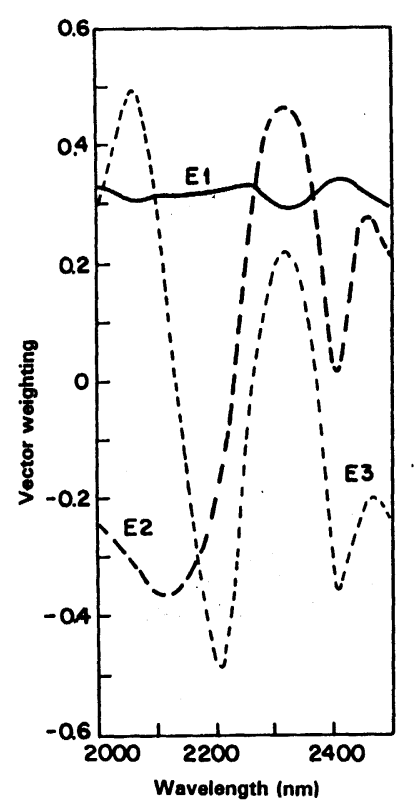

Figure 8. Vector weighting of three principal components (E1, E2 and E3) derived from 10 reflectance values within the wavelength interval of 2000 to $2500 \mathrm{~nm}$, obtained from spectra scaled to unit at $1500 \mathrm{~nm}$. 


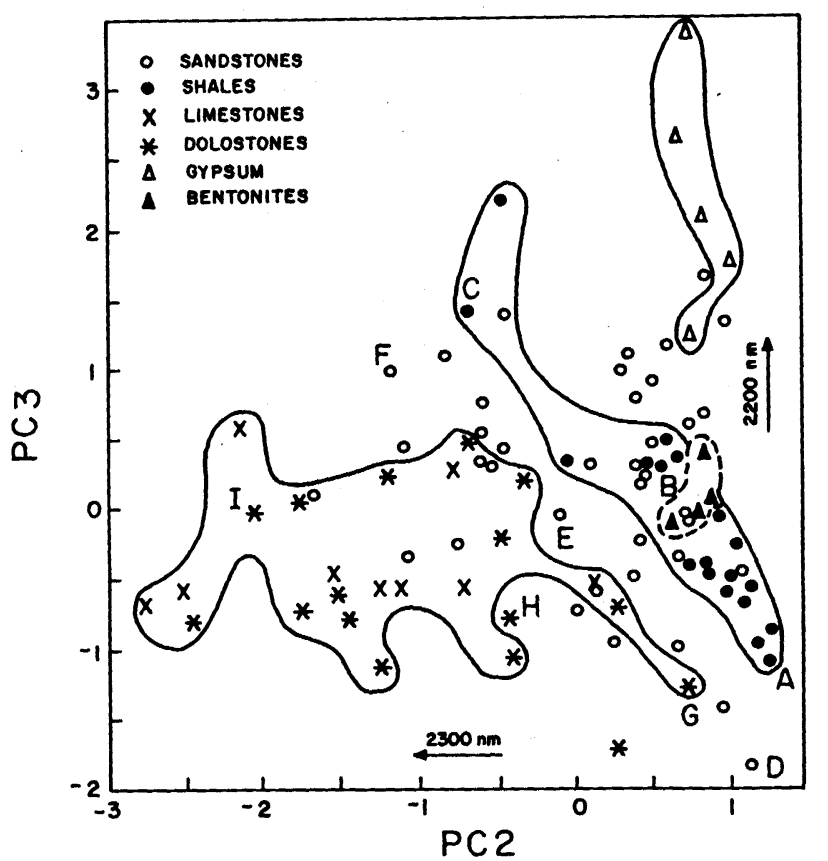

Figure 9. Second and third principal components scores of the 94 scaled spectra in the interval of 2000 to $2500 \mathrm{~nm}$. Carbonates, shales, bedded gypsum and bentonites are enclosed by lines to facilitate visualization of their distribution. Spectra of samples identified by letters are shown in figure 10 .

towards the left of PC2. Samples from Goose Egg, Madison and Alcova are found in the extreme left side of the diagram. Similarly, because of the relations of the $2200 \mathrm{~nm}$ feature with PC3, bedded gypsum samples are located in the upper right side. Clean sandstones and shales are found in the lower right side because their spectra are featureless. In general, there is more scatter in the PC space of the scaled spectra (figure 9) than in the PC space of the original data (figure 5), even though some groups remain clustered such as the Mowry, Thermopolis, Goose Egg and Madison, which is an indication of stratigraphic homogeneity.

To illustrate the above relations, we selected in figure 9 three sets of spectra of shales, sandstones and dolostones which are identified by letters and displayed in figure 10. As we go from the lower right side towards the upper left side of figure 9 , the samples show spectra with increasingly stronger features at $2200 \mathrm{~nm}$ (mostly in the shales of figure $10(a)$, and at $2300 \mathrm{~nm}$ (mainly in the dolostones of figure $10(c)$. On the other hand, the broad feature from 2050 to $2100 \mathrm{~nm}$ becomes prominent in any sequence of spectra in the opposite direction (see spectra $F, E$ and $D$ in figure 10). In the space distribution of figure 9 , neighbouring samples tend to display similar spectra. See for instance spectra $F$ in figure $10(b)$ of a Crow Mountain calcareous sandstone, and spectra $C$ in figure $10(a)$, of a Red Peak dolomitic mudstone. Another example of spectral similarity is observed in spectra $D$ in figure $10(b)$, of a Cloverly quartzarenite, and spectra $G$ in figure $10(c)$, of a Goose Egg dolostone. 

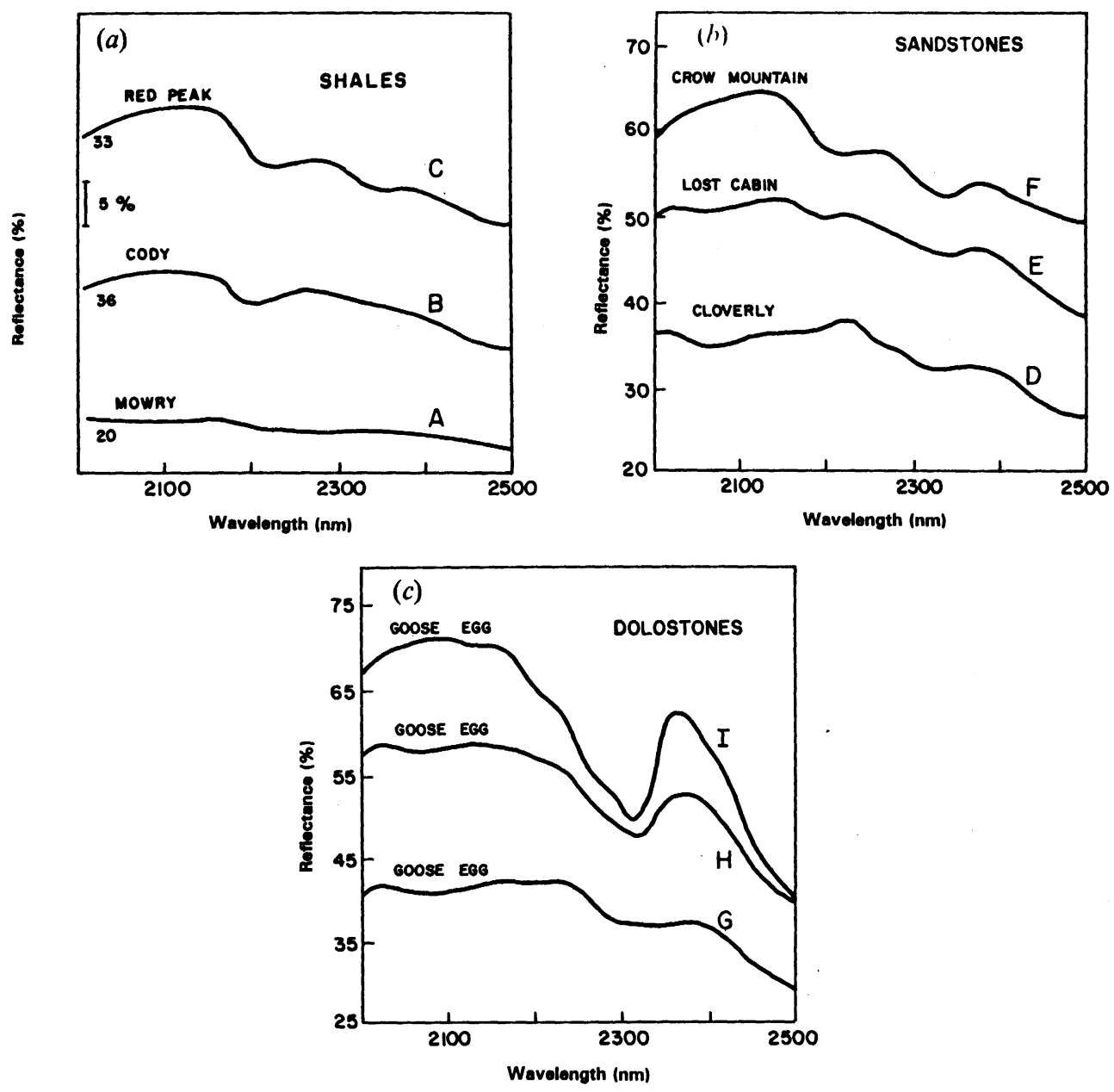

Figure 10. Spectra of shales, sandstones and dolostones are shown respectively in $10(a),(b)$ and $(c)$. In $10(a)$, the curves have been offset vertically and the reflectance values at $2000 \mathrm{~nm}$ are indicated. See figure 9 for the position of each curve in the PC space.

\subsection{Analysis of absorption bands by continuum removal}

The featureless spectrum $A$ in figure 6 is a typical example of a Thermopolis black shale with a relatively large amount of organic matter. Low albedo shales result from the presence of opaque carbonaceous material, which masks the absorption bands of the other components (Hunt and Salisbury 1976). Shales that contain small amounts of organic carbon usually display spectra with higher albedo and more well-defined bands. For example, spectrum $E$ in figure $7(a)$ exhibits asymmetric and broad 1410 and $1910 \mathrm{~nm}$ absorption bands characteristics of smectite spectra (Hunt 1977, Lang et al. 1990).

Spectra of sandstones from the Wind River and Bighorn basins generally show 1400,1900 , and $2200 \mathrm{~nm}$ bands due to hydroxyl and/or molecular water. Sometimes, $1400-1410 \mathrm{~nm}$ and $2160-2200 \mathrm{~nm}$ band pairs indicate the presence of kaolinite in the samples. Spectra $G$ and $H$ in figure $7(b)$ exhibit a $2340 \mathrm{~nm}$ feature probably 
associated with calcite. The presence of this mineral in these samples was also confirmed through XRD analysis supplied by Lang et al. (1990).

For spectra of limestones and dolostones, the most important feature to be observed is the carbonate band around $2300 \mathrm{~nm}$. Bands with centres at $2340 \mathrm{~nm}$ are characteristic of calcite and those at $2320 \mathrm{~nm}$ are diagnostic of dolomite (Hunt and Salisbury 1971, Gaffey 1986, Lang et al. 1990).

For the majority of the spectra, features short of $1000 \mathrm{~nm}$ can be attributable to iron oxide phases (Townsend 1987). These features can include a weak band at $650 \mathrm{~nm}$ (e.g., spectrum $\mathrm{G}$ in figure $7(b)$ ) or a more well-defined band at $900 \mathrm{~nm}$ (e.g., spectrum $L$ in figure $7(c)$ ). Another common iron feature is the steep reflectance falloff, from the red to the blue wavelength, observed in many curves (e.g., spectrum I in figure $7(b))$.

In the present work, we used the straight-line continuum method (Clark and Roush 1984) to calculate parameters describing the 900,1400,1900, 2200 and $2300 \mathrm{~nm}$ absorption bands. Our statistical analysis indicated that the best absorption band parameters to differentiate the stratigraphic units studied were the depth and the area of absorption bands, especially bands centred at 1900, 2200 and $2300 \mathrm{~nm}$. Depth and area were found to be highly correlated.

In figures 11 and 12, we display the depth relations of 1900 versus $2300 \mathrm{~nm}$ and of 1900 versus $2200 \mathrm{~nm}$, respectively. Group separability may be estimated by inspection of the space distribution of the samples. For instance, we can observe in figure 11 that the $2300 \mathrm{~nm}$ band can separate the carbonates from the siliciclastics, because they present deeper bands than the latter. In figure 12, the diagram shows that the $2200 \mathrm{~nm}$ band depth can separate the Mesaverde sandstones from the other siliciclastics, because they present deeper $2200 \mathrm{~nm}$ bands. In the same diagram, the shales are found in the lower left side because they have shallower bands at 1900 and $2200 \mathrm{~nm}$. The $1900 \mathrm{~nm}$ band can separate the Tensleep and Mesaverde sandstones from the other sandstone groups. However, the $1900 \mathrm{~nm}$ band is also affected by atmospheric absorption, a major hindrance in remote sensing. In essence, the analysis of absorption bands by continuum removal corroborates the results obtained from the second and third PCA of scaled spectra (figure 9).

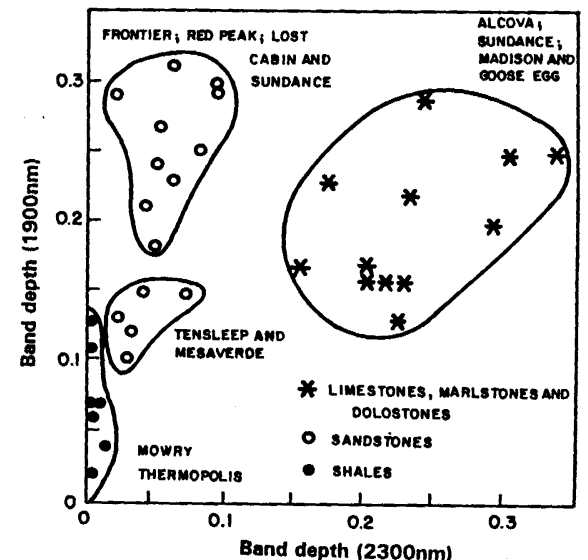

Figure 11. Outlines of zones enclosing samples from stratigraphic units distinguished by band depths 1900 versus $2300 \mathrm{~nm}$. Band depth is defined in figure 3 . 


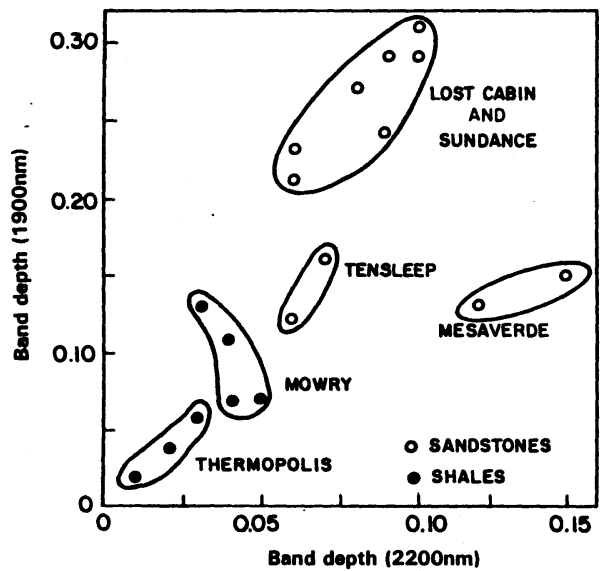

Figure 12. Outlines of zones enclosing samples from stratigraphic units distinguished by band depths 1900 versus $2200 \mathrm{~nm}$. Band depth is defined in figure 3 .

\subsection{Spectral reflectance-lithostratigraphy}

To facilitate lithostratigraphic inferences, we have plotted the studied reflectance parameters (band, PC scores and absorption band parameters) as vertical log sections along the stratigraphic column. We concluded that the PC scores can represent adequately all these parameters with a minimal redundancy.

Figure 13 summarizes our results in a log-format that provides a preliminary overview of the Wind River and Bighorn reflectance-lithostratigraphy. In terms of albedo variations, the $\mathrm{PCl}$ of the original data shows, in ascending stratigraphic order, a Paleozoic sequence with spectra having comparatively higher albedos, with above 50 per cent reflectance. The Mesozoic interval, from the Red Peak to Sundance, presents intermediate albedo, around 35 per cent reflectance. This is followed by a low albedo interval, with less than 25 per cent reflectance, of samples from the Morrison to the Mowry formations. The upper sequence, mostly sandstones, is characterized by intermediate albedo.

Positive PC2 scores of the original data indicate spectra with descending slopes in the infrared region, while negative values are associated with ascending slopes.

The PC2 of scaled spectra is useful in distinguishing carbonate-bearing from carbonate-barren strata because of the $2300 \mathrm{~nm}$ absorption feature. In the PC3 of scaled data, the highlighted samples are bedded gypsum related to the $2200 \mathrm{~nm}$ band. The presence of kaolinite, muscovite, smectite and illite would also generate absorption features around this wavelength.

A major flaw in the sections presented in figure 13 is the lack of control in the stratigraphic position of each sample within the unit. However, this is not the case of the 'Curtis Sand' and the 'Rusty Beds', positioned at the top of the Sundance and at the base of the Thermopolis, respectively. Another inaccuracy is related to lithologic heterogeneity that is not represented completely by the field samples of the data set.

Nevertheless, the sections presented in figure 13 demonstrate the potential value of reflectance-lithostratigraphy. For instance, the horizontal dashed lines indicate the presence of important marker beds described by Lang et al. (1990): the bedded gypsum of the Dinwoody, Goose Egg and Gypsum Springs; the algal marlstone of 


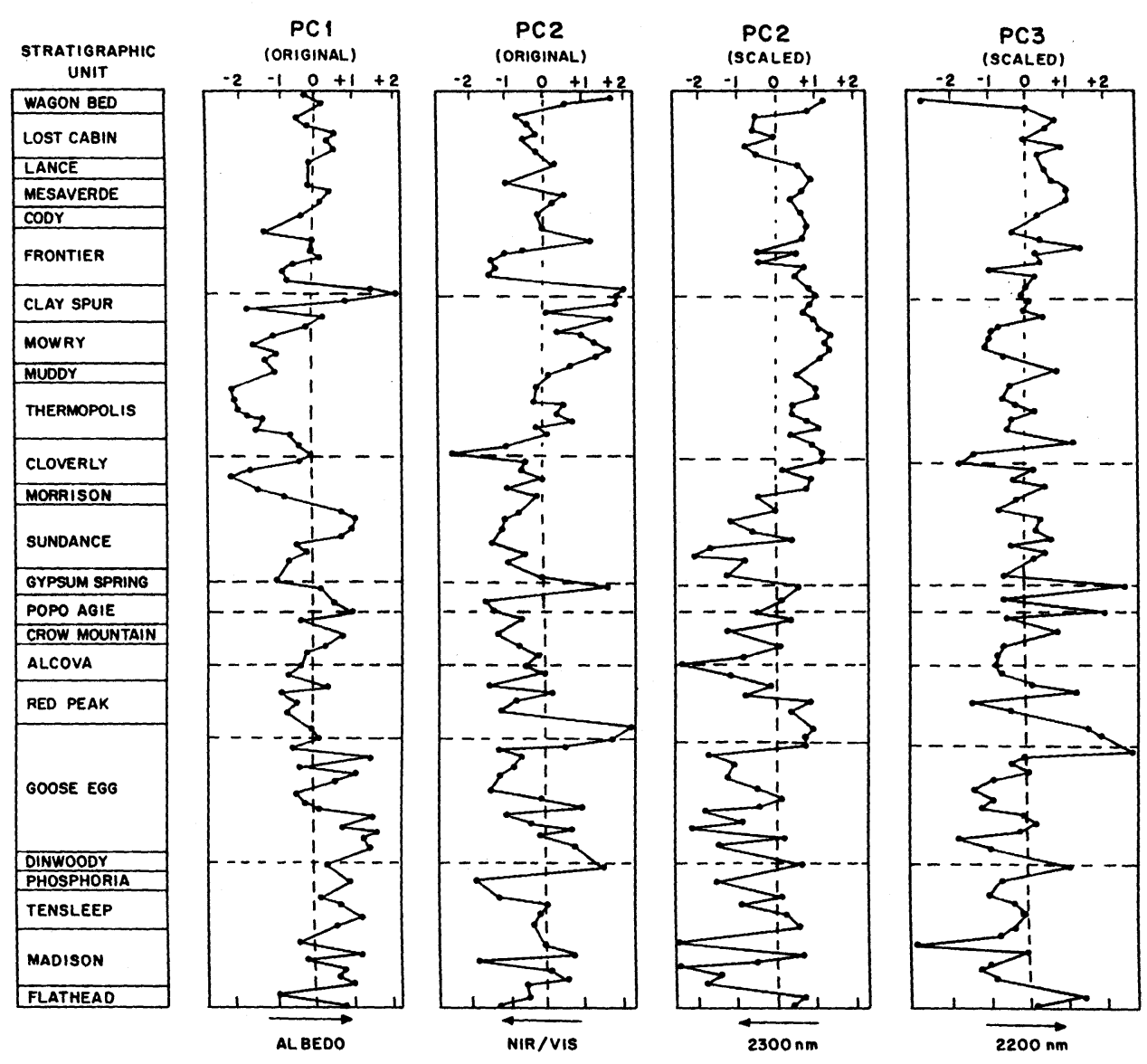

Figure 13. Schematic representation of $\mathrm{PC}$ score variations along the stratigraphic column $\mathrm{PCl}$ and $\mathrm{PC} 2$ of the original data and PC2 and PC3 of the scaled data. Horizontal dashed lines indicate possible reflectance key markers.

the Alcova Member; the analcime-rich mudstone of the Popo Agie Member; the kaolinite-rich sandstone of the Cloverly Formation; and the smectite-rich shale of the Clay Spur Bentonite. In general, these marker beds can be spectrally identified by at least one of the four PC values.

In figure 13, a fifth data set could also include information related to 'spectral mineralogy', identified by the wavelength position of absorption band centres. For example, the possibility of identifying calcite and dolomite bearing strata is of general value in analyses of carbonate facies (Lang et al. 1990).

\section{Conclusions}

Our study has shown that the spectra of outcrop samples from Wind River and Bighorn basins can be quantitatively distinguished on the basis of albedo, shape and slopes of the curves and major absorption features. Stratigraphic units composed of samples with homogeneous reflectance properties presented tighter clusters in PC space. PCA was an efficient statistical procedure to investigate the source of spectral variance and to visualize the separation and similarity among samples from distinct stratigraphic units. The absorption band analysis by continuum removal confirmed 
the PCA results of scaled spectra. PCA log sections plotted along the stratigraphic column provide the manner by which reflectance characteristics may be compared and possible key markers identified for lithostratigraphic correlations. Once complete reflectance-lithostratigraphic patterns have been established within stratigraphic sections, they may be utilized to correlate lithofacies within a series of sections or to search for missing sections adjacent to structural discontinuities.

\section{Acknowledgments}

The authors are grateful to Dr Harold R. Lang for providing the data base and for reviewing the original manuscript and also to two anonymous reviewers. Lênio S. Galvão was supported by a CAPES scholarship during the period of this investigation.

\section{References}

Clark, R. N., and Roush, T. L., 1984, Reflectance spectroscopy: quantitative analysis techniques for remote sensing applications. Journal of Geophysical Research, 89, 6329-6340.

Conel, J. E., Lang, H. R., Paylor, E. D., and Alley, R. E., 1985, Preliminary spectral and geologic analysis of Landsat-4 thematic mapper data, Wind River basin area, Wyoming. I.E.E.E. Transactions on Geoscience and Remote Sensing, 23, 562-573.

Davis, J. C. 1986, Statistics and data analysis in Geology (New York: John Wiley).

GAFFEY, S. J., 1986, Spectral reflectance of carbonate minerals in the visible and near infrared (0.35-2.55 microns): calcite, aragonite, and dolomite. American Mineralogist, 71, $151-162$.

Galvão, L. S., Vitorello, I., and Paradella, W. R., 1995, Spectroradiometric discrimination of laterites with principal components analysis and additive modeling. Remote Sensing of Environment (In Press).

HUNT, G. R., 1977, Spectral signatures of particulate minerals in the visible and near-infrared. Geophysics, 42, 501-513.

Hunt, G. R., and Salisbury, J. W., 1971, Visible and near infrared spectra of minerals and rocks: II. carbonates. Modern Geology, 2, 23-30.

HUNT, G. R., and SalisburY, J. W., 1976, Visible and near infrared spectra of minerals and rocks: XI. sedimentary rocks. Modern Geology, 5, 211-217.

LANG, H. R. (editor), 1985, Report of the workshop on geologic applications of remote sensing to the study of sedimentary basins, held in Lakewood, Colorado, on 10-11 January 1985. Jet Propulsion Laboratory Publication 85-44 (Pasadena, CA: Jet Propulsion Laboratory).

lang, H. R., Adams, S. L., Conel, J. E., McGuffie, B. A., Paylor, E. D., and Walker, R. E., 1987, Multispectral remote sensing as stratigraphic and structural tool, Wind River basin and Bighorn basins areas, Wyoming. American Association of Petroleum Geologists Bulletin, 71, 389-402.

Lang, H. R., Bartholomew, M. J., Grove, C. I., and Paylor, E. D., 1990, Spectral reflectance characterization $(0.4$ to 2.5 and 8.0 to $12.0 \mu \mathrm{m})$ of phanerozoic strata, Wind River basin and southern Bighorn areas, Wyoming. Journal of Sedimentary Petrology, 60, 504-524.

SaSaki, K., KaWATA, S., and Minami, S., 1983, Constrained nonlinear method for estimating component spectra from multicomponent mixtures. Applied Optics, 22, 3599-3603.

SMITH, M. O., Johnson, P. E., and AdAMS, J. B., 1985, Quantitative determination of mineral types and abundances from reflectance spectra using principal components analysis. Journal of Geophysical Research, 90, C797-C804.

Stucky, R. K., LaNG, H. R., Krishtalka, L., and ReDline, A. D., 1987, Analysis of Eocene depositional environments: preliminary TM and TIMS results, Wind River basin, Wyoming. Proceedings of the International Geoscience and Remote Sensing Symposium Ann Arbor, MI, U.S.A. 18-21 May 1987. (New York: I.E.E.E. Inc.), pp. 1163-1168.

TowNSEND, T. E., 1987, Discrimination of iron alteration minerals in visible and near-infrared reflectance data. Journal of Geophysical Research, 92, 1441-1454. 